\title{
I am surrounded by death: death as a defining psychic issue within a relational psychoanalytic engagement and the impact of the therapist's relationship with death
}

\author{
Zelda Gillian Knight \\ Department of Psychology, Faculty of Humanities, Auckland Park Campus, University of Johannesburg, Johannesburg, South Africa
}

\begin{abstract}
Taking inspiration from Frommer, this paper is part of a shift towards incorporating death as a defining psychic issue. With a sense that I am surrounded by death, the author presents two brief vignettes of clinical cases to illustrate the impact of the therapist's relationship with death on the therapeutic process. Each case shows a different level of engagement with the client when the focus is on death-talk, and reflects, on the one hand, the therapist's ability and readiness to work with death as an object of analysis, and on the other hand, the therapist's lack of processing of experiences of death of others, and the resultant failure to successfully work with death in analysis. The one case is arguably more successful therapeutically than the other, and highlights some issues that come into play in the light of the therapist's relationship with death. These issues are: i) the importance of the therapist's development with regards to processing experiences of death and dying cannot be underestimated when working with death as an object of scrutiny; ii) empathy remains core to the process and getting in touch with how the client experiences the death of the other. Without recognition, however, no (grief) work can begin. The therapist needs to psychologically recognise the other to be able to connect to, and empathize with, the clients process; iii) the impact of the death of the other often transforms into the work of the impact of the death of self; iv) if clients have a sense that the therapist knows what they are speaking about because the therapist has done some of the work of making meaning of death, clients may feel more confident in working with death as an object of analysis.
\end{abstract}

Key words: Death; Psychoanalytic; Intersubjective.

\section{Introduction}

An article by Martin Frommer (2016) inspired this essay. He said that Despite profound changes that have taken place in psychoanalytic theory and practice over

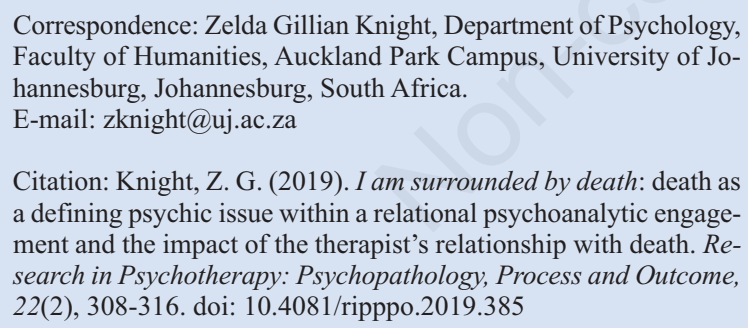

Citation: Knight, Z. G. (2019). I am surrounded by death: death as a defining psychic issue within a relational psychoanalytic engagement and the impact of the therapist's relationship with death. Research in Psychotherapy: Psychopathology, Process and Outcome, 22(2), 308-316. doi: 10.4081/ripppo.2019.385

Conflict of interest: the author declares no potential conflict of interest.

Funding: none.

Received for publication: 25 February 2019.

Revision received: 30 April 2019.

Accepted for publication: 30 April 2019

This work is licensed under a Creative Commons Attribution NonCommercial 4.0 License (CC BY-NC 4.0).

${ }^{\circ}$ Copyright: the Author(s), 2019

Licensee PAGEPress, Italy

Research in Psychotherapy:

Psychopathology, Process and Outcome 2019; 22:308-316

doi:10.4081/ripppo.2019.385 the last several decades, the human awareness of mortality continues to be treated as if it were not a defining psychic issue (p. 374). He also noted that while contemporary psychoanalysis has become a place of intersubjective engagement in helping minds formulate and metabolize various and often potentially overwhelming experiences, the relational turn has not yet fully considered the need of the solitary mind to be joined in confronting its own eventual demise. Freud (1923) understood death as hard to conceptualize because it is not experienced and, therefore, it remains theoretical or abstract. As such, it is not represented in the unconscious. While Freud (1920) described the theory of the death instinct, this theory did not include the psychic impact or significance of having to die.

Moreover, theorist Donald Winnicott (1965) rejected Freud's ideas of instinctual drives in terms of human motivation, and thus, he did not accept the death instinct (Modell, 1985). While the work of Winnicott is relational in terms of the development of the self, he did not directly focus on death of self as a defining issue in analysis.

In pointing out how Freud (1915c) thought of death as challenging to represent psychically, and that he essentially gave death no psychic significance whatsoever to death, Martin Frommer (2016) laments this current absence of death's psychic importance in psychoanalytic therapy and theory.

While large bodies of psychoanalytic literature contribute significantly to an understanding of how people experience loss and grief following death (Beyers, Ralli- 
son, \& West, 2017; Bouchal, Rallison, Moules, \& Sinclair, 2015; Davis, Deane, \& Lyons, 2015; Holland \& Neimeyer, 2010; Reeves, 2011) and that this more recent research on grief shows a moving away from stage and task-oriented models to loss as re-conceptualized as an event that will change mourners' identity over time (Beyers et al., 2017), another growing body of psychoanalytically-informed research offers new perspectives on the lack of death as a psychic issue, and thus the awareness of actual death, and death anxiety, for both therapist and client (Becker, 1973; Coen, 2010; Hoffman, 1998, 2013; Frommer, 2005, 2016; Piven, 2003; Razinsky, 2013; Slavin, 2011, 2013, 2016; Stolorow, 2007; Yalom, 2008). Emerging out of this developing literature is the critique that in the past death anxiety was viewed not so much about death per se, as it was about other anxieties related to early or infantile fear of abandonment and separation, as well as early anxieties of castration and the unthinkable terror of annihilation (Piven, 2003). The actual fear of death, notes Frommer (2016), is thereby lodged within a theoretical framework that robs it of its legitimacy.

Within contemporary psychoanalytic theory that seeks to include death as a psychic issue, the theory of annihilation anxiety cannot be reduced to death anxiety (Hoffman, 2013). Hoffman suggests that early traumatic experiences may produce a sense of the boundaries of self disintegrating and dissolving, and thus can be a precursor to death anxiety. It is, however, not the same as death anxiety. The experience of the self dissolving, which may be understood as an imminent psychic death, is, Frommer (2016) asserts, distinctly different from the total absence of experience - the nothingness of death. Annihilation anxiety is not about the fear of non-existence. It's about something more terrifying than nothingness: the experience of being present and witnessing the process of one's self shattering, and the ensuing disconnection both to oneself and to others (p. 378).

In his essay Slavin (2016) noted that in the 1970s Ernest Becker (1973) attempted to bring some aspects of this existential dread of actual death to Freudians who, like Freud, were unable to give existential anxiety or anxiety about loss per se - a central place in their thinking. Slavin (2011) points out that Freud had invented the death instinct as a higher level drive that, in turn, evaded the question of anxiety about mortality. Later, Slavin (2016) declared that Melanie Klein, a closer follower of Freud, was equally unable to accord the existential dimension any reality in her work, and in fact, she reinforced Freud's death drive (Frommer, 2005, 2016).

Using his personal relationship with mortality as a crucial variable in how to work with a client who had an overwhelming fear of death, Frommer (2016) successfully managed to assist the client confront her fear of death. In this case study, Frommer was able to succinctly present $a$ psychoanalytic meeting ground in relation to mortality, to make meaning in the presence of mortality, and to not avoid the so-called void created by death but to conjure the emptiness of death (p. 374). It is noted that his own relationship with death was a major contributing factor in their intersubjective engagement (Aron, 1996) which opened up frank discussion about death and dying of self and other. Frommer's work, therefore, showed how the therapist's conceptualization of death impacts on the analytical material that emerges when such discussion is about the death of self.

In this light of a move towards locating death as a defining psychic issue within psychoanalytic psychotherapy and theory, it is acknowledged that people have various perceptions and thoughts about death. For many people death is not final, nor one of emptiness, terror and dread. For these people, religion or/and a belief system about death produces a perspective on death that is entirely different to those who believe there is no afterlife. Based on such perceptions of death, clients will approach death differently in the therapeutic dialogue. However, it is also viewed that regardless of how death of self and other is thought about, death remains a core existential issue that binds humanity (Slavin, 2011) and as such, therapeutic intersubjective dynamics and processes that underlie thoughts of dying create a psychic space and place that allows for death to be a defining psychic issue (Frommer, 2016).

A crucial element that emerges from this literature that views death as a defining psychic issue in psychoanalytic psychotherapy (Becker, 1973; Hoffman, 1998, 2013; Frommer, 2005, 2016; Piven, 2003; Razinsky, 2013; Slavin, 2011, 2013, 2016) is the therapist's relationship with death.

\section{What this article is about}

Taking inspiration from Frommer (2016), this paper is a continuation of the trend for the inclusion of death of self as a central and defining psychic issue in psychoanalytic theory and practice. To this end, this paper is located within the intersubjectivity positioning of the analytical relationship (Aron, 1996; Aron \& Starr, 2013) and seeks to emphasize the impact of the therapist's relationship with death of self and other when death is the object of scrutiny. With a sense that I am surrounded by death, the author presents two brief vignettes of clinical cases to show the influence of the therapist's process and processing, or lack of processing, of death on the therapeutic engagement. Each case shows a different level of dialogue with the client with the subject of death, and reflects, on the one hand, the therapist's ability and readiness to work with death as a subject matter, and on the other hand, the therapist's lack of processing of experiences of death of others, and the resultant failure to successfully work with death. It is unique in that it adds to the dialogue some issues that come into play in the light of the therapist's relationship with death when the object of analysis is death. 


\section{I am surrounded by death}

About a year ago, I was sitting under a large, towering old oak tree having a relaxed lunch with my life partner when I suddenly heard the ominous sharp bullet-like crack of a large overhanging branch as it began to break and fall. With only seconds to warn my partner, who had his back to the drama, that he needed to get up quickly and get away from the table, the branch fell. We both managed to jump out of our chairs and dive across the lawn. I found myself, however, suddenly pinned beneath the enormous fallen branch. I was injured but alive. While still pinned down, I looked across to where the table and chairs had been standing to see that they were smashed to pieces and almost unrecognizable. My first thought was I could have been killed. I eventually got up off the ground with the help of my partner and a small gathering crowd. I gingerly made my way to another chair to sit down and gain some kind of stability from the shock of what had just happened. I was shaken and bleeding, but I felt an intense gratitude that I was alive.

Three months later, I was with four close family members at the bedside of my partner's 92 year old mother as she lay in a hospital bed dying. She was small, thin, frail, and unconscious as we touched her and held her hand, knowing her last moments were close at hand. She was well loved by all. As she struggled to breathe, the family encouraged her to let go and be at peace and assured her that it was okay to pass to the other side. At some point during the early hours of the morning as we stood there next to her, I was aware of how her small, bony chest had stopped rising and falling. She had died. I looked for a while at her face. She seemed so peaceful. The weird thing was that her heart pace maker continued to work, and so her heart continued to beat, and the monitor above her bed continued to beep on in the otherwise silence of the room. While she was dead, and becoming pale bluish in complexion, we stood next to her body and waited a further one hour for the heart pace maker to stop. In that time, in the presence of death so close, I tried to make sense of death.

A few months later, the wife of my partner's adult son and mother of his two young grandchildren committed suicide. It was a shock to everyone. While I was not much involved in that part of the life and family of the adult son, I was involved in the process of my partner as he tried to make sense of this event.

About two years prior to the death of this young mother, I attended the memorial of a distant family friend who had also committed suicide.

As I write this essay, a close friend of ours has just buried his dearly beloved father.

I am surrounded by death.

Five years ago, my father died of old age. Eight years ago, my mother died of old age. Both were in their 80s. At the time I did not grieve, nor speak much about their death. My only sibling was living overseas and was not involved in their lives. I felt frozen at the time of their death, and for many years after, was unable to cry or scatter their ashes.

When the tree branch fell on me, when I witnessed the old mother of my partner die, when the distant friend of the family killed himself, when the wife of my partner's son took her life, when my parents died, I thought to myself - I am surrounded by death.

\section{Death as object of analysis}

At about the same time as my father's death five years ago, when I had not processed their death and dying, and when I was still holding onto their ashes, 32-year-old Janet (the name Janet is a pseudonym. All identifying data mentioned have been disguised to protect the identity of the client) came for therapy because her father had just died. She told me how dreadfully painful it was to not have him anymore in her life, how lonely she felt without him; how she wished she could still to talk to him. She sobbed.

Janet: I don't believe in the afterlife or God or anything, so I am not sure what has happened to him, or where he is, or what it is like to die, to be dead. I think that I make sense of it all by thinking he is within me now, that he is still alive in memory form inside me, that I carry him about within me and he is not completely dead because of this. If I think too much about it, I also realize that while he is a memory for me, he is also very much dead.

While she sobbed and cried, I felt detached. I don't remember much what I replied.

Janet: It seems like he is both alive within me but also really dead and absent. I feel sometimes so sad, but also afraid now of my own death. I don't want to die. I have too much to live for. I don't want to be non-existent and just a memory. I am afraid of just becoming a memory.

Therapist: You don't want to die.

While I did follow her line of thought and feelings, I did not feel connected to her experience. Janet came for a few more sessions, and then left. I knew I had messed things up and that I did not want to delve into anything about what she had brought up in me.

Uncannily I did not have a case like Janet's until more recently.

After my near-death experience with the fallen oak tree branch, as well as the other deaths that followed, and a sense that I am surrounded by death, I began to process my parents' death. This lead to my confrontation with my fears and anxieties of death and dying. Still in a raw and early stage of self-analysis and deep reflection of those deaths, 28-year-old Casper (the name Casper is a pseudonym. All identifying data mentioned have been disguised to protect the identity of the client) came to therapy. His father had just died several months before from a longterm illness. Psychically I was ready for Casper. He 
evoked in me a courage to walk with him as he processed his own loss and pain because I had begun the process of working though my losses and frozen grief. Unlike with Janet I felt a connection to young Casper.

Casper: My father died some months ago.

Therapist: I am sorry to hear that. How are you feeling?

Casper: Lost, I think. He was always a huge source of support to me. I loved him. Now I am alone. I feel lost without him. Empty. Like there is a gap inside me.

Therapist: if I understand you correctly, his death has left a hole inside you.

At this stage, I remembered the feelings I had experienced as I began to process the death of my parents. They were similar to Casper's feelings of having a gap inside left by the absence of the beloved.

Casper: Yes that is correct, a deep black hole. I wonder about death a lot now. I don't believe in an afterlife so I think it is harder to feel assured that he is okay somewhere. Floating in a good dark and just being okay. I wonder about dying, how it feels to die. I think about my own death and dying.

Therapist: When you think about your own death and dying, what comes to mind?

Casper: Fear. I am afraid of dying. I don't want to die. It is like a deep black hole through which I fall through. It is a lonely thing.

At this point, I remembered the elderly mother of my partner as I witnessed her dying and death. I remembered the hospital bed with her lying on it, and how she seemed so frail and almost invisible.

Therapist: Can you maybe share a bit more about your fear of dying, of falling through this deep black hole?

Casper: It is a place of darkness. To die is to become nothing. I am afraid of this dark nothing. I am afraid of being nothing, just perhaps some memory for someone in the family. I am afraid of being like my father, a person that does not exist anymore. All he did, all he loved, all he was is now just a memory, but he is no longer existing.

Therapist: If I hear you correctly, the fear of dying is the fear of being nothing, of not existing anymore. Death for you is a dark nothing.

Casper: Yes, that is right. It is a dark place of nothing. In fact, if I think about it, it is nothing. Death is just nothing. I once had minor surgery and the doctors used a process called 'conscious sedation' which meant I was given this drug which allowed them to operate on me while I was awake. I felt nothing, no pain as they cut into me, no sense of being aware but apparently, I did speak to them and yet I don't remember speaking. I had no memory, no consciousness of anything. I think death is like that, it is nothing, a dark place of nothing, perhaps not even dark, just nothing. It is not even non-being because that means I must be conscious of a state of non-being. I would be conscious of having a consciousness of something called non-existence...so in my thoughts, death is nothing, like the sedation I had. There is no memory, no pain, just nothing.

Therapist: Correct me if I am wrong here but what I hear is the nothingness of death, and that it is hard to imagine death because it requires a consciousness that is not there. I wonder what this fear you speak about is.

Casper: Yes, that is it. I fear the process of dying. I think that my death itself is shifting from a reality of something into nothingness. Nothingness is just nothing. It is not even another reality. I won't feel anything, just when I had the operation under conscious sedation. I am afraid of dying itself, of the point of letting go into the nothingness. I am scared of my own death. I like to think my father is waiting for me on the other side, but I know he is not there. He has gone. I think that death itself, the process of letting go into death and non-being is terrifying and I think I will want to push towards life and not non-being.

Therapist: if I am understanding you correctly, you fear the process of dying, of moving into nothingness. Death is nothingness for you. You fear your own dying and letting go into the nothingness. Without a father waiting for you, letting go into death is terrifying. You can't save yourself from death.

Casper: Yes exactly... when I come to think of it, it is the terror of being alone, of going through this death and dying process alone. There is no one to help you. Death is a lonely process, and I think the terror is that one must go through this without anyone. I am afraid of being alone even if there are a hundred people besides my bed that is if I am dying on a bed, it is still me dying alone.

I had a flash back to the mother of my partner lying on the hospital bed, dying with us surrounding her.

Therapist: Tell me more about your sense of dying alone

Casper: I am terrified of it, of being alone at a point where I let go into nothingness, into death. I feel a rising panic and yet also, what is the meaning then of my life if I just become nothing, alone in the nothingness. I won't know anything because death is nothing, but I feel terror in being alone in dying. It makes me feel crazy. Death is a boundary then, in a real sense, between my life and my nothingness. Do you know what it feels like to have this boundary, to know about mortality, to understand non-existence?

Therapist: Yes, I do know what you are speaking about.

Casper: I am relieved you know what I am speaking about. It feels comforting to know you understand me.

Therapist: Knowing I understand you makes it less daunting to talk about dying. In the past, I would have been shifting things away from speaking about death. I have been processing some of my own fears of dying. I think this has made it easier for me to relate to your experience. I understand what you mean.

Casper: It feels good to know that you do understand what I am saying. I feel I can talk more about it because 
you are also trying to make sense of death. It helps me so much to know that you hear me and won't try to shift my focus away from my fear of my death.

Therapist: I am glad you feel that way.

Casper: I want to say also that I just missed being killed. A few months back, I was in a car accident. I saw, at close range, the other car slam into me. I was dazed but uninjured. In that moment, I realized how finite and fragile my life really is. I suddenly understood that at some point I am going to die. I never thought about it much. When my father died, I felt the fear of my own death. After the accident, I felt more terror of dying.

Therapist: If my understanding is correct, it seems that both your father's death and your near-death experience in the car accident has made you become aware of death. You realize how fragile your life is and that it can be over, gone, finished in just a second. Yes, you could have died. If I am understanding you correctly, your experience of nearly being killed brings home to you a sense of mortality.

Casper: Yes it does. I will die someday. I nearly died, and my father did die. I feel that his death and my own near miss has become some kind of defining thing for me. I am young to be dealing with this kind of thing, and I can feel that my own mortality has given me some kind of boundary in which I can live a life despite the fact that it will end someday, that I will die.

Therapist: Tell me more about living a life despite it going to end someday.

\section{The importance of the therapist's relationship with death when death is the object of analysis}

\section{The importance of the therapist's processing of experiences of death of other}

In the beginning with Janet, I was in denial about my parents death, or rather, I blocked off the pain of their absence. My grief was frozen. This frozen and un-metabolized experience is conceptualized as the unexperienced experience (Browne, 1990. Browne defined this concept of the unexperienced experience as the idea that when something happens to us that is negative, we do not experience all of it at once. In this way, experiencing is a process that takes place over time), a concept which foreshadowed the notion of unformulated experience (Stern, 1997) which assumes that some unwanted or negative experiences are outside of consciousness, and thus unformulated or unprocessed. Such unformulated experience remains unconscious unless it is made conscious, unless it is symbolized. When Janet arrived to see me, the death of my parents had remained unspoken, unnamed and unthinkable. As a result, it remained locked inside the vault within my unconscious. If the therapist, as I was, is blocked in processing the loss of loved ones through death, clients like Janet will not find a pathway in the intersubjective relationship in which to navigate, symbolize and release their pain and loss. In other words, my frozen and blocked grief process froze and blocked Janet's process of talking about death. My encapsulated cocoon of dissociation, and thus my inability to confront my experiences of death and loss, obstructed Janet's ability to confront her experiences of death and loss. The therapeutic process was doomed to fail, and Janet (disappointed and unhealed) left soon after a few sessions. My response of you don't want to die was the nearest I think I got to reaching out to her in her pain and grief. My loss of memory as to what else I may have said indicates to me my dissociation at the time. At the time, I was vaguely aware that her leaving was a reprieve for me against facing the pain of loss. I am also aware that in order to preserve some kind of sanity or stability and omnipotence, the therapist can create a barrier that forecloses possibilities for developing relational experience in the therapy (Harris, 2009). For me taking sanctuary in narcissism and omnipotence was to protect against the stormy sense of non-being, of the nothingness of death. Not being ready to work with her experiences of death and loss negatively impacted on her process as much as her process impacted on me.

The implication is that unprocessed experiences of death (and any other traumatic experiences) are wedged within an unknown unconscious as repressed material but, as Freud noticed, they still continue to influence conscious life (Freud, 1915a, 1915b). When the subject of death is a part of the intersubjective engagement, when what is unspoken becomes spoken, it potentially becomes the return of the repressed (Freud, 1915a, 1915b). This means that the unconscious repressed material begins to be formulated. My encounter and experience within the intersubjective relationship with Janet included a small beginning of an inner push and nudge to begin to process the death of my parents, to formulate the unformulated. Long after she had departed, Janet remained in my mind. When clients remain in your mind, it is sometimes an indication of your unfinished business. Perhaps because she spoke of death so openly, and despite my inability to genuinely reach out to her because of my dissociation, our engagement was significant for me in that it initiated my long over-due exploration the impact of my parents' death. Over time, this process, while my failings with Janet remained alive in me, transformed into the confrontation with my frozen grief and pain - the return of the repressed. The return of the repressed took many shapes and forms, from anger and sadness, to loss and oceans of tears and pain, and finally to a dread of my own death.

I am reminded of the work of Kohut (1977) who argued that the greatest importance in psychoanalytic therapy is given to the unblocking and facilitation of strangulated development; and whatever promotes that goal becomes a part of the therapeutic strategy. While this notion refers to the client in therapy, the importance of the therapist's development cannot be underestimated. In this case, unblocking my frozen grief and strangulated devel- 
opment, and in turn, the confrontation with the notion of the death of the self, and what this may mean for self and other, is crucial for the development of the intersubjective relationship. When Casper came to see me a few years after Janet had left, it was the right time for me not because I had figured out everything regarding the death of my parents but because I was, at least by then, processing the impact of my own mortality in the light of feeling that I am surrounded by death.

At that time when Casper and I were working together, I had had my frightening near-death experience, witnessed the death and dying of a beloved mother, been to several funerals, and wept years of frozen tears for my dead parents. At a phenomenological level, I had an on-going nagging and nudging waft of fear of my own demise and death. At other times, I experienced sporadic spurts of terror and a sense of the absolute absurdity of life. When I linked to the terror, it was a panicky feeling of the existential meaninglessness of life, as so succinctly described by Yalom (2008). When I thought more about my mortality, I lived life as if I would never die because I could not conceptualise death as anything but nothing. It was not even a state of non-being because that assumes a consciousness of a state in the first place.

With Casper, in contrast to Janet, the experience of therapy was significantly different because I was in the process of processing my own mortality. It is often in the wake of the deaths of significant others that one begins to confront one's own mortality. The death of others activates existential issues of death and life. With Casper the analytic material was co-created and shaped by, on the one hand, my inner transformation with regards to being surrounded by death, and on the other hand, by his own material of death and dying. The analytical third (Ogden, 2004) would have been made up of our joint unconscious processes surrounding our experiences and thoughts about death and dying. As my relationship to death was qualitatively different at the time of Casper's encounter with me, I could engage more authentically with his process of death and loss.

In summary, the importance of the therapist's development with regards to processing experiences of death and dying cannot be underestimated when working with death as an object of scrutiny.

\section{Empathy and recognition and its links to the therapist's capacity for engagement}

When Casper had said to me that his father had died several months ago, I responded with genuine empathy and told him, I am sorry to hear that. How are you feeling? With Janet, there was some empathy but the full extent of it was limited because I had not yet processed my own loss of both parents. Empathy is a powerful dynamic that facilitates connection. I am reminded of the work of Richard Geist (2013, p. 276, italics in original) when he wrote that the empathic process unfolds when we imagi- natively feel and think our way into another's life, experience his or her world from the patient's subjective vantage point, and convey our understanding of what we experience to the patient in a way that invites the patient to emend, clarify, or correct our understanding in the context of our own subjectivity. Geist noted that on the one hand, it is a dynamic reaching out to understand our patient's subjectivity, and on the other hand, it is an active or implicit invitation to the patient to empathically search out the therapist's personality, theory, and style of relating, for without knowing and experiencing the therapist's subjectivity, the patient will not know what affective states the therapist can manage.

In other words, the empathic process plays a role and the determination of the depth and breadth of affective connections that will emerge in the patient therapist relationship. The key for me is the ability to climb inside the subjective world of the other in order to really understand and make a connection, and then to convey such understanding. Moreover, in my experience, empathy is linked to a recognition of the subjectivity of the other (Benjamin, 2004; Orange, 2010) or the experience of the other, and in this case, Casper's loss. Without recognition, no (grief) work can begin. With Janet, I did not recognise her experience of loss because I did not recognise my own experience of loss, and thus she could not manage the painful feelings because I was not attuned or supportive (Kohut, 1977) and containing (Bion, 1962). With Casper, this was a different experience for me, and for him. His experience (of loss) was recognised because I had recognised such experiences in me first and before our encounter; his experience was formulated because mine had been formulated. Recognition of loss is particularly important when working with experiences of loss through death. Recognition of loss invites clients, like Casper, to explore their feelings of loss, and delve into their unconscious mind where things of pain and loss have yet to be spoken. After my reply, (I am sorry to hear that. How are you feeling?) Casper was comfortable to respond to me and describe his feelings - Casper had said, Lost, I think ... I feel lost without him. Empty. Like there is a gap inside me.

Unlike with Janet because I was shut down and closed off with regards to my unprocessed loss, Casper's experience was recognised and validated. I was able to stay psychologically close with him, and responded by saying, His death has left a hole inside you. In my reverie at this point, I was thinking about the death of my parents and what the experience of their absence meant. I too felt the hole inside me that they had left, but it was less raw for me then as I had had time to process it. With Casper, however, the absence of the father was new and thus still tender and sore. It can be seen in our conversation at this point about death that my quality of communication and engagement with Casper was much more intense and real than it was with Janet.

In summary, empathy remains core to the process and 
getting in touch with how the client experiences the death of the other. Without recognition, however, no (grief) work can begin. The therapist needs to psychologically recognise the other to be able to connect to, and empathize with, the clients process.

\section{The death of other as trigger for explorations of the death of self}

When he spoke about his experience of his father's death, it moved him quickly into a process of thinking about his own death and dying. First-hand experience of death of a loved one, if such experience is allowed to unfold, often evokes thoughts about one's own death. When my parents died, with no recognition of the loss, my mortality was not a subject in my mind. With Casper, however, I was in a different psychological state of being. I had processed some of the feelings of a gap inside me, and my thoughts about my mortality had begun to become more localised. Casper had said, I wonder about death a lot now...I wonder about dying, how it feels to die. I think about my own death and dying.

This is a point where the work of the impact of the death of the other often merges into the work of the impact of the death of self.

With a sense of I am surrounded by death in the wake of my experience of several close and loved people around me dying, and that I was processing my own mortality in the light of my recent near-death experience, I replied to Casper by a question formulated to continue the conversation - When you think about your own death and dying, what comes to mind? When there is death-talk like this, and it is not shut down by the therapist's unformulated experiences of loss, it shifts the intersubjective relationship towards an engagement of two minds meeting that continue to form an analytic third (Ogden, 2004) that is imbued with death and dying.

Casper's replied, I am afraid of dying. I don't want to die. It is like a deep black hole through which I fall through ...To die is to become nothing. I am afraid of being nothing... (death is) a dark place of nothing. In fact, if I think about it, it is nothing. Death is just nothing. Here Casper perhaps picked up the unconscious communication from me that death is nothing. I had not mentioned anything to him about my thoughts about death, and when he spoke of his fear of dying, it resonated with me. At this point in the session, my reverie was of the death of my partner's mother. The moment of watching her die was an extraordinary psychic event and a pivotal moment. Psychically, things shifted in me about death and dying, and in the wake of my recent near-death experience, I found that I was focusing and re-focusing on my own death. Months afterwards, I grappled with the making some sense of death, especially my own inevitable death. It was about then that we had a suicide in the family and, consequently, I began to conceptualize death as nothing.

Death anxiety, however, is a common phenomenon
(Frommer, 2016; Slavin, 2016). If death anxiety is relocated in psychoanalytic theory as a defining psychic issue, such anxiety is not only viewed as anxiety about death of self (as opposed to anxieties about separation, abandonment, annihilation and castration) but it will begin to shape and define the contents of the conscious and unconscious mind, and in this way, shape and structure the self.

As the therapy progressed, Casper shared more of his thoughts of death and dying. He made sense of the experience by relating it to his experience of conscious sedation. While this gave him some meaning, he followed it up again with the thought that, I like to think my father is waiting for me on the other side, but I know he is not there. He has gone. Casper touched on the idea of the existential loneliness of death, that it was for him the terror of being alone... There is no one to help you. Death is a lonely process...one must go through this without anyone. I am afraid of being alone even if there are a hundred people besides my bed that is if I am dying on a bed, it is still me dying alone. In that moment, for a second or so, this aloneness of death that Casper conveyed, resonated for me. When he spoke of the loneliness, I felt something come together inside me, like a piece of a jigsaw puzzle connecting to the bigger picture. In the intersubjective relationship, my experience of death and dying blended and merged with his thoughts about the loneliness of death. When he spoke about dying in a bed, I remembered the old mother dying in a bed, surrounded by family. I wondered in that moment with Casper if she felt lonely, or was she aware at some level of us next to her. My thoughts later were that she had no idea we were there, and she had no sense of anything, not even loneliness. I asked Casper - Tell me more about your sense of dying alone because this would invite him to explore more his mortality.

As indicated earlier, little is said in psychoanalytic theory about the existential issue of dying. Less is mentioned of the therapist's relationship with death when death is the object of scrutiny. Processing my experiences with death and loss, and the sense that - I am surrounded by deathmeant that death had become a psychic event for me as it had defined my sense of self as I am going to die one day. Casper replied, I am terrified of it, of being alone at a point where I let go into nothingness, into death. I feel a rising panic and yet also, what is the meaning then of my life if I just become nothing, alone in the nothingness. It was evident that Casper's thoughts about his death was one of terror but it was more than this. As a psychic event that shaped and formatted his sense of existence, it required (again) a recognition from the other (me in this case). Casper needed to know that I knew what he was talking about when he referred to death and dying. He needed to have my recognition of his experience. He asked me, Death is a boundary then, in a real sense, between my life and my nothingness. Do you know what it feels like to have this boundary, to know about mortality, to understand non-existence? Do you know what it feels 
like to have this boundary, to know about mortality, to understand non-existence?

In summary, the impact of the death of the other often transforms into the work of the impact of the death of self.

\section{Clients' sometimes need to know that the therapist knows}

Do you know was an important connecting to me theme of Casper's as he grappled with his mortality. I could have said many things and given some interpretation as to question his need to know my experience, instead, I answered - Yes, I do know what you are speaking about. I shared a little about my process and my fears of dying. Subsequently, he was relieved to know that I knew what he was speaking about; it gave him refuge in this connection and tie. What is necessary for this kind of connection is the therapist's personal confrontation with death, death anxiety, and the thinking and processing of the death of self. Without my process of I am surrounded by death, I could not have a relationship with death which would enable the development of our intersubjective experience, I could not say to him that I knew. When it comes to thoughts and processes regarding mortality of the self in analysis, an experience of the death of close others and/or a near-death experience, creates a deep connection and inter-mingling of death thoughts in the intersubjective relationship. An experience with the therapist knowing what they are speaking about (and this knowing is based on the therapist's experience of confrontation with death) is also equally important for clients because it gives legitimacy to their experience, and it grounds it in a feeling of being understood and recognised. Otherwise, death-talk in therapy remains at the intellectual level. This again speaks to the importance of the therapist's relationship with death when death is the topic of the therapeutic work. If I had said to Casper that I did not know what he was talking about with regards to death, it is reasonable to assume that the session would have taken a different course. It may have avoided any further work with the client's experiences, and like Janet, Casper may have found help elsewhere.

This knowing that I know initiated another ensuing conversation about his near-death experience. He told me that as a result of his near-death experience, he realized how finite and fragile his life is, and he said, I nearly died. It is unlikely that he would have told me about this experience unless had he had a sense that I would know what he is talking about, and understand it. The impact of his near-death experience, similarly to my near-death experience, was a profound realization of our mortality. It is interesting at an unconscious level of communication, that Casper mentions this experience much later. In my mind, this event is a turning point in Casper's life in relation to how Casper makes sense of his mortality. This is evident when he said, I feel that his death and my own near miss has become some kind of defining thing for me. This state- ment highlights the impact of death of self and other in relation to the sense of self. It can be suggested that this kind of experience changed him at the existential level of being because it is an existential issue to ponder the death of self.

In summary, if clients have a sense that the therapist knows what they are speaking about because the therapist has done some of the work of making meaning of death, clients may feel more confident in working with death as an object of analysis.

\section{Conclusions}

Slavin (2016) asserted that for the last several centuries many early and later modernist, existential thinkers (from Kierkegaard, through Nietzsche, Heidegger, Camus, Sartre, Becker, Hoffman, to Stolorow) have taken as their starting point the reality that most of everything we hold dear to us will not last.

Without, that is, never-ending efforts at building goodenough meanings in face of a haunting, background awareness of our allotted speck of time, on a speck of a planet, in an infinite universe. Endlessly, we need to discover, create, and recreate transitional space - our subjective world...from birth onward, a void, some would say an abyss - a nothingness - reveals itself at the edge, just under the surface, of the subjective universe (p. 542).

In the light of the above, I am reminded of Hoffman's (1998) words that humanity continues on not despite life's transience but because of it. In this way, our clients will make meaning of life just as they try to make meaning of death. When our clients shift attention onto death and loss, as Janet and Casper did, it is crucial that the therapist can be attuned to this death-talk, to recognise and understand what is happening to their clients, and step alongside their clients struggle to make sense of death. When death of self and other becomes an object of analysis, the analytic third (Ogden, 2004) becomes infused with death and dying, and all unconscious material is influenced by this.

In this paper, the main premise is a call to join in the movement towards incorporating death as a defining psychic issue. Two brief vignettes of clinical cases were presented to not only illustrate this but to show the impact of the therapist's relationship with death on the therapeutic process. The one case described showed a markedly more successful therapeutically engagement than the other case, and highlighted some important points that emerged in the context of the therapist's relationship with death. These were: i) the importance of the therapist's development with regards to processing experiences of death and dying cannot be ignored when working with death as an object of scrutiny; ii) in connecting to the client and the client's experience of the death of the other, it seems that empathy remains fundamental. Without recognition of the other's subjectivity in terms of death-talk, it is evident that no 
(grief) work can begin. Furthermore, such recognition permits, to some extent, a deep connection to, and empathy with, the clients process; iii) the impact of the death of the other often transmutes into a confrontation with the impact of the death of self; iv) if clients know that the therapist knows what they are speaking about in terms of death because the therapist has done some of the work in making meaning of death, it appears that clients may feel more open to working with death as an object of analysis.

\section{References}

Aron, L. (1996). A meeting of minds: Mutuality in psychoanalysis. Hillsdale, NJ: The Analytic Press.

Aron, L., \& Starr, K. (2013). A psychotherapy for the people: Toward a progressive psychoanalysis. New York, NY: Routledge.

Becker, E. (1973). The denial of death. New York, NY: Free Press.

Benjamin, J. (2004). Beyond doer and done to: An intersubjective view of thirdness. The Psychoanalytic Quarterly, 73, 546. doi: 10.1002/j.2167-4086.2004.tb00151.x

Beyers, J. M., Rallison, L., \& West, C. (2017). Dialogical space in grief work: Integrating the alterity of loss. Death Studies, 41(7), 427-435. doi: 10.1080/07481187.2017.1288666

Bion, W. (1962). Learning from experience. New York, NY: Basic Books.

Bouchal, S. R., Rallison, L., Moules, N. J., \& Sinclair, S. (2015). Holding on and letting go: Families' experiences of anticipatory mourning in terminal cancer. OMEGA - Journal of Death and Dying, 72(1), 42-68. doi: 10.1177/0030222 815574700

Browne, I. (1990) Psychological trauma, or unexperienced experience. Re-vision, 12, 21-30.

Coen, S. J. (2010). The dead self must be reborn. In S. Akhtar (Ed.), The wound of mortality. New York, NY: Aronson.

Davis, E. L., Deane, F. P., \& Lyons, G. C. B. (2015). Prediction of individual differences in adjustment to loss: Acceptance and valued-living as critical appraisal and coping strengths. Death Studies, 40, 211-222. doi: 10.1080/07481187. 2015.1122677

Freud, S. (1915a). Repression. Standard edition of the complete psychological works of Sigmund Freud, 14, 141-158. London, UK: Hogarth Press.

Freud, S. (1915b). The unconscious. Standard edition of the complete psychological works of Sigmund Freud, 14, 161216. London, UK: Hogarth Press.

Freud, S. (1915c). Thoughts for the times on war and death. Standard edition of the complete psychological works of Sigmund Freud, 14, 273-300. London, UK: Hogarth Press.

Freud, S. (1920). Beyond the pleasure principle. Standard edition of the complete psychological works of Sigmund Freud, 18, 1-64. London, UK: Hogarth Press.

Freud, S. (1923). The ego and the id. Standard edition of the complete psychological works of Sigmund Freud, 19, 1-66. London, UK: Hogarth Press.

Frommer, M. (2016). Death is nothing at all: On contemplating non-existence. A relational psychoanalytic engagement of the fear of death. Psychoanalytic Dialogues, 26, 373-390. doi: 10.1080/10481885.2016.1190599

Frommer, M. S. (2005). Living in the liminal spaces of mortality.
Psychoanalytic Dialogues, 15, 479-498. doi: 10.1080/ 10481881509348845

Geist, R. (2013). How the empathic process heals: A microprocess perspective. International Journal of Psychoanalytic Self Psychology, 8(3), 265-281. doi: 10.1080/ 15551024. 2013.800357

Harris, A. (2009). You must remember this. Psychoanalytic Dialogues, 19, 2-21. doi: 10.1080/10481880802634537

Hoffman, I. (1998). Ritual and spontaneity in the psychoanalytic process: A dialectical-constructivist view. Hillsdale, NJ: The Analytic Press.

Hoffman, I. (2013). Response to Slavin: Considering the evolutionary and existential contexts of dialectical constructivism. Psychoanalytic Dialogues, 23, 315-323. doi: 10.1080/ 10481885.2013.794645

Holland, J. M., \& Neimeyer, R. A. (2010). An examination of stage theory of grief among individuals bereaved by natural and violent causes: A meaning-oriented contribution. OMEGA - Journal of Death and Dying, 61(2), 103-120. doi: 10.2190/OM.61.2.b

Kohut, H. (1977). The restoration of the self. Madison, CT: International Universities Press.

Modell, A. H. (1985). The works of Winnicott and the evolution of his thought. Journal of the American Psychoanalytic Association, 33, 113-137.

Ogden, T. (2004). The analytic third: Implications for psychoanalytic theory and technique, Psychoanalytic Quarterly, 73, 167-196.

Orange, D. (2010). Recognition as intersubjective vulnerability in the psychoanalytic dialogue. International Journal of Psychoanalytic Self Psychology, 5, 227-244. doi: 10.1080/ 15551024.2010.491719

Piven, J. (2003). Introduction. The Psychoanalytic Review, 90, 395-402. doi: 10.1521/prev.90.4.395.23918

Razinsky, L. (2013). Freud, psychoanalysis and death. London, UK: Cambridge University Press.

Reeves, N. (2011). Death acceptance through ritual. Death Studies, 35(5), 408-419. doi: 10.1080/07481187.2011.552056

Slavin, M. O. (2011). Lullaby on the dark side: Existential anxiety, making meaning and the dialectic of self and other. In L. Aron \& A. Harris (Eds.), Relational psychoanalysis: Vol. 4: Expansion of theory (pp. 391-413). Hillsdale, NJ: The Analytic Press.

Slavin, M. O. (2013). Meaning, mortality, and the search for realness and reciprocity: An evolutionary/existential perspective on Hoffman's dialectical constructivism. Psychoanalytic Dialogues, 23, 296-314. doi: 10.1080/ 10481885.2013.794643

Slavin, M. O. (2016). Relational psychoanalysis and the tragicexistential aspect of the human condition. Psychoanalytic Dialogues, 26, 537-548. doi: 10.1080/10481885.2016. 1214465

Stern, D. (1997). Unformulated experience. Hillsdale, NJ: The Analytic Press.

Stolorow, R. (2007). Trauma and human existence: Autobiographical, psychoanalytic and philosophical reflections (Psychoanalytic Inquiry Book Series; Vol. 23). London, UK: Taylor \& Francis.

Winnicott, D. W. (1965). The maturational processes and the facilitating environment. London, UK: The Hogarth Press.

Yalom, I. (2008). Staring at the sun: Overcoming the terror of death. San Francisco, CA: Jossey-Bass. 